\title{
Continuous Catalyst-Free Esterification of Oleic Acid in Compressed Ethanol
}

\author{
Ana Carolina de Araujo Abdala, ${ }^{1}$ Vitor Augusto dos Santos Garcia, ${ }^{2}$ \\ Caroline Portilho Trentini, ${ }^{3}$ Lúcio Cardozo Filho, ${ }^{4}$ Edson Antonio da Silva, \\ and Camila da Silva ${ }^{3,4}$ \\ ${ }^{1}$ Program of Post-Graduation in Bioenergy, West Paraná State University, Faculdade Street 645, Jardim La Salle, \\ 85903-000 Toledo, PR, Brazil \\ ${ }^{2}$ Department of Food Engineering, College of Animal Science and Food Engineering, University of São Paulo, \\ R. Duque de Caxias Norte 225, 13635-900 Pirassununga, SP, Brazil \\ ${ }^{3}$ Department of Technology, Maringá State University, Avenue Dr. Ângelo Moreira da Fonseca 1800, 87506-370 Umuarama, PR, Brazil \\ ${ }^{4}$ Department of Chemical Engineering, Maringa State University, Avenue Colombo 5790, 87020-900 Maringa, PR, Brazil
}

Correspondence should be addressed to Camila da Silva; camiladasilva.eq@gmail.com

Received 5 October 2013; Revised 30 October 2013; Accepted 6 November 2013; Published 19 January 2014

Academic Editor: Dmitry Murzin

Copyright (C) 2014 Ana Carolina de Araujo Abdala et al. This is an open access article distributed under the Creative Commons Attribution License, which permits unrestricted use, distribution, and reproduction in any medium, provided the original work is properly cited.

\begin{abstract}
The esterification of oleic acid in a continuous catalyst-free process using compressed ethanol was investigated in the present study. Experiments were performed in a tubular reactor and variables investigated were temperature, pressure, and oleic acid to ethanol molar ratio for different residence time. Results demonstrated that temperature, in the range of $473 \mathrm{~K}$ to $573 \mathrm{~K}$, and pressure had a positive effect on fatty acid ethyl esters (FAEE) production. In the experimental range investigated, high conversions can be obtained at low ethanol concentrations in the reaction medium and it was observed that oleic acid to ethanol molar ratios greater than $1: 6$ show no significant increase in conversion. Nonnegligible reaction conversions (>90\%) were achieved at $573 \mathrm{~K}, 20 \mathrm{MPa}$, oleic acid to ethanol molar ratio of $1: 6$, and 20 minutes of residence time.
\end{abstract}

\section{Introduction}

Fatty acid, methyl or ethyl, esters can be usually obtained from free fatty acid (FFA) esterification reaction, through vegetable oils hydrolysis followed by the fatty acid esterification or from direct vegetable oils transesterification [1]. The importance of examining the esterification reaction in a more detailed manner is justified by the huge amount and variety of vegetable oils worldwide available for biodiesel production which may have a high percentage of FFA making the conventional alkali-catalyzed transesterification impracticable, since for this process the percentage of FFA needs to be less than $0.5 \%$ [2]. Recent studies propose to obtain esters in two reaction steps of substrates with high acidity, consisting of two approaches: (a) esterification of FFA and subsequent transesterification of triglycerides [3-5] or (b) hydrolysis of triglycerides, followed by esterification of fatty acids obtained [6-8]. In these approaches are commonly used chemical catalysts (homogeneous or heterogeneous) or enzymatic catalysts. More recently, the noncatalytic process where is proposed the hydrolysis occurs primarily in subcritical water and subsequent esterification using a solvent in subor supercritical $[9,10]$.

According to the current literature, catalyst-free reactions at high temperature and pressure conditions provide improved phase solubility and decreased mass-transfer limitations; the reaction rate increases significantly in the supercritical state and, thus, the reaction is complete in shorter periods and simpler separation and purification steps $[11,12]$. Some studies available in the literature reported the biodiesel production from free fatty acids (FFA) by noncatalytic method at sub- and supercritical conditions and these studies reported batch reaction with methanol [13-18], ethanol [19], and dimethyl carbonate [20] or reaction in 
continuous mode with ethanol [21] and methanol [22]. As it can be verified, the use of compressed ethanol to FFA esterification in continuous mode is little explored in the literature as well as the effect of process variables: temperature, pressure, and molar ratio. The obtention of these data is necessary for understanding the kinetics of production of fatty acids esters which are used to evaluate the continuous production of biodiesel from oils with high acidity in pressurized medium. Feedstock flexibility is the most important aspect to consider for biodiesel production, since the cost of the raw materials currently represents about $70 \%$ of the total production cost [23].

In this sense, the present work attempts to contribute to build a platform for biodiesel production in continuous mode with alcohol at sub- and supercritical conditions exploring key raw materials. Here, the main objective was to investigate the noncatalytic esterification of oleic acid in continuous mode. For this purpose were the effects of temperature assessed in the range of $473 \mathrm{~K}$ to $598 \mathrm{~K}$, pressure from $15 \mathrm{MPa}$ to $20 \mathrm{MPa}$, and oleic acid to ethanol molar ratio of $1: 3$ to $1: 12$ for different residence time.

\section{Materials and Methods}

2.1. Materials. Oleic acid (FMaia) and ethanol (JT Baker $99.8 \%$ ) were used as substrates in the esterification reactions. In step titration of samples ethanol $95 \mathrm{wt} \%$ (Vetec), ethyl ether (Nuclear), sodium hydroxide (Nuclear), and phenolphthalein indicator (Nuclear) were used. All other reagents and solvents were of analytical grade.

2.2. Apparatus and Experimental Procedure. Esterification reactions were carried out in duplicate using a tubular reactor made of stainless steel tubing (316 L 1/4 in OD inner diameter $3.2 \mathrm{~mm}$ ) and stainless steel tubing (304 L $30.5 \mathrm{~mm}$ OD inner diameter $13 \mathrm{~mm}$ HIP) packed with glass beads $(4.5 \mathrm{~mm}$ diameter). The substrates were placed in a closed Erlenmeyer and mixed by means of a mechanical stirring device and then charged into the reaction system by a high-pressure liquid pump. The reactor was placed in a furnace with controlled temperature, monitored by three thermocouples directly connected at the inlet and outlet of the reactor. The system pressure was controlled by a back-pressure valve and monitored by a pressure indicator. In this work the residence time was computed by dividing the void volume of the reactor $(\mathrm{mL})$ by the flow rate of substrates $\left(\mathrm{mL} \mathrm{min}^{-1}\right)$ set in the liquid pump. More details in relation to the experimental apparatus can be found in the work of [24].

Samples were collected periodically in a glass vial placed at the reactor outlet after reaching the steady state condition, that is, after a reactor space-time had been elapsed at least three times.

2.3. Analysis of Free Fatty Acid (FFA). Samples were first submitted to ethanol and water evaporation to constant weight in a vacuum oven. The percentage of free fatty acid was determined based on the method Ca 5a-40 [25], which is based on acid-base titration using as titrant methanol solution of potassium hydroxide $(\mathrm{KOH})$ previously standardized.
Since each sample was performed in duplicate, data were subjected to one way ANOVA and Tukey test $(P>0.05)$ evaluating differences in treatment means. The free fatty acid content of the sample is defined as follows:

$$
\text { FFA content }(\mathrm{mg} / 100 \mathrm{mg})=\frac{282 M V}{10 m},
$$

where $M$ is the molar concentration of $\mathrm{KOH}, V$ is the volume of $\mathrm{KOH}$ used in the titration process, and $m$ is the sample weight.

Once the FFA content is determined, the oleic acid (OA) conversion can be calculated as follows:

$$
\text { AO conversion }(\%)=\frac{\mathrm{FFA}_{0}-\mathrm{FFA}_{t}}{\mathrm{FFA}_{0}},
$$

where $\mathrm{FFA}_{t}$ and $\mathrm{FFA}_{0}$ are free fatty acid content at residence time and initial time, respectively ( $\mathrm{mg}$ of FFA/100 $\mathrm{mg}$ of sample).

\section{Results and Discussion}

3.1. Effect of Oleic Acid to Ethanol Molar Ratio. To evaluate the effect of oleic acid to ethanol molar ratio, experiments were performed at $573 \mathrm{~K}$ and $598 \mathrm{~K}$ in the range of $1: 3$ to $1: 12$ with results presented in Figure 1 . Increasing the molar ratio oleic acid: ethanol of $1: 3$ to $1: 6$ resulted in increased oleic acid conversion. At $573 \mathrm{~K}, 20 \mathrm{MPa}$, and 20 minutes of residence time, $\sim 84 \%$ of conversion was obtained at oleic acid to ethanol molar ratio of $1: 3$ and $\sim 92 \%$ at oleic acid to ethanol molar ratio of $1: 6$. In catalyst-free reactions an increase of alcohol in the reaction medium should provide greater contact between substrates, thus favoring reaction conversion. Besides, an excess of reactant could also shift the reaction to ethyl esters formation [11]. Alenezi et al. [14] reported that the increase in molar ratio FFA : methanol of $1: 0.7$ to $1: 3$ increased yield of esters obtained by noncatalytic esterification of FFA at batch mode with supercritical methanol of $50 \%$ to $90 \%$ at $543 \mathrm{~K}, 10 \mathrm{MPa}$, and $20 \mathrm{~min}$ of residence time. The positive effect of molar ratio on the esterification of oleic acid and methanol was also reported by Ding et al. [16] that reported, at $583 \mathrm{~K}$ and 20 minutes of reaction, yields of $70 \%$ and $90 \%$ for oleic acid to methanol molar ratio of $1: 1$ and $1: 4$, respectively. Cho et al. [18] reported the esterification of palm fatty acid distillate (PFAD) with methanol in a semibatch reaction and obtained at $563 \mathrm{~K} / 0.86 \mathrm{MPa}$ and 25 minutes about $30 \%$ and $60 \%$ of conversion for methanol flow rate of $1.2 \mathrm{~g} / \mathrm{min}$ and $3.6 \mathrm{~g} / \mathrm{min}$, respectively.

The increase of the ethanol concentration in the reaction medium, in experiments with molar ratios of $1: 9$ and $1: 12$, does not significantly increase the conversion of reaction $(P>$ 0.05). For the supercritical esterification of oleic acid with dimethyl carbonate conducted in a batch-type reactor, Ilham and Saka [20] observed that values of molar ratio above 1:6 (oleic acid : dimethyl carbonate) did not cause an increase of the conversion, being reported at $373 \mathrm{~K} / 9 \mathrm{MPa}$ and $15 \mathrm{~min}$ of residence time conversions of $\sim 88 \%$ at $1: 6$ to $1: 40$. A similar effect is reported by Ding et al. [16] in the range of oleic acid to methanol molar ratio of $1: 4$ to $1: 18$. 


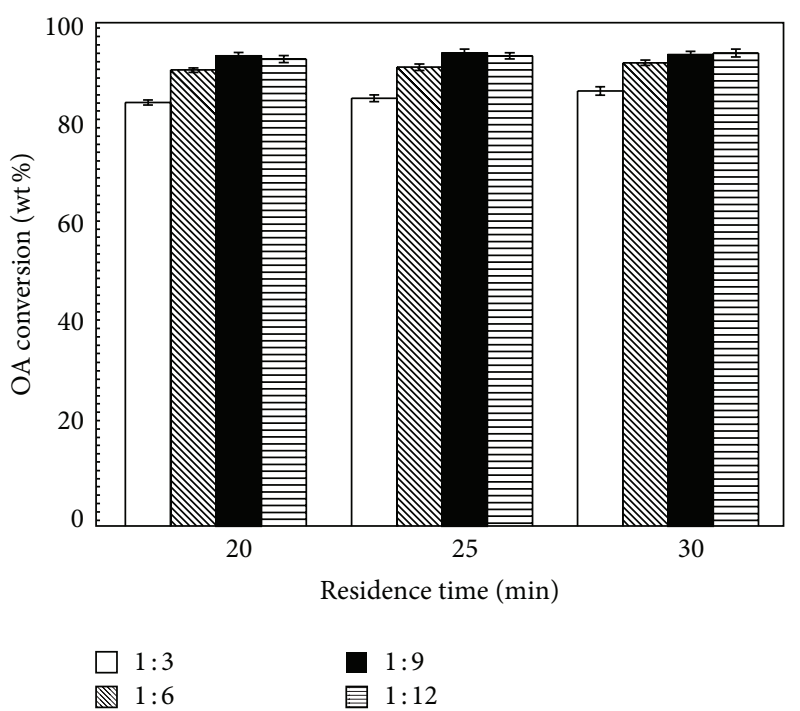

(a)

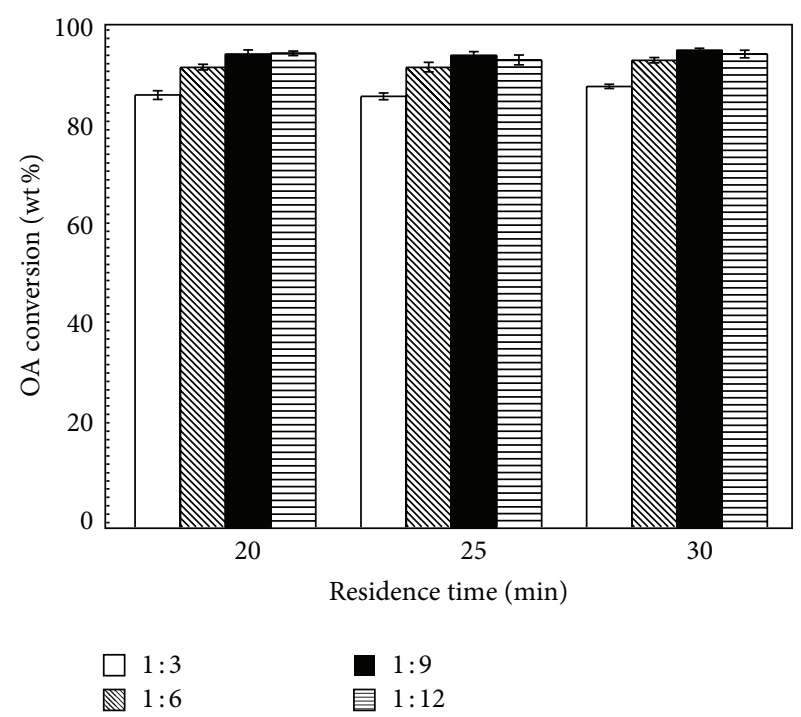

(b)

FIGURE 1: Effect of molar ratio on the conversion of oleic acid to pressure $20 \mathrm{MPa}$ and temperature: $573 \mathrm{~K}$ (a) and $598 \mathrm{~K}$ (b).

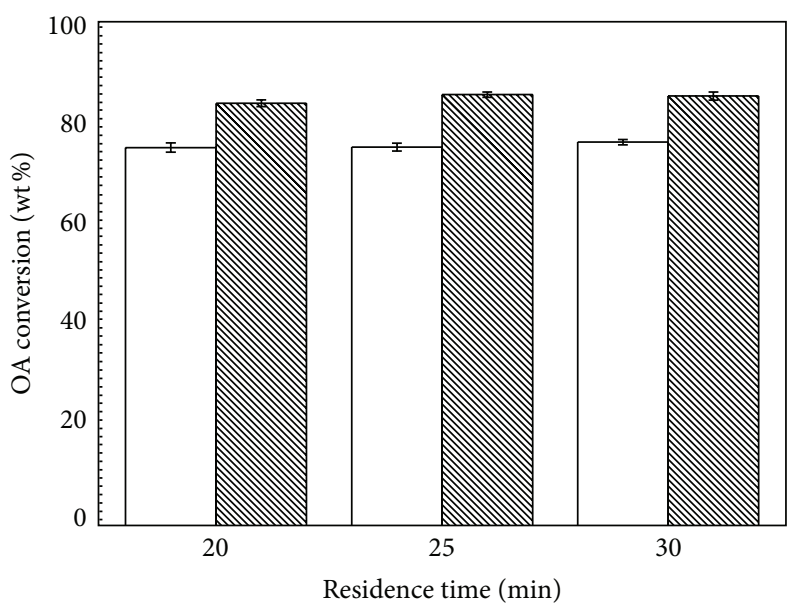

$\square 15 \mathrm{MPa}$

$\mathbb{\$} 20 \mathrm{MPa}$

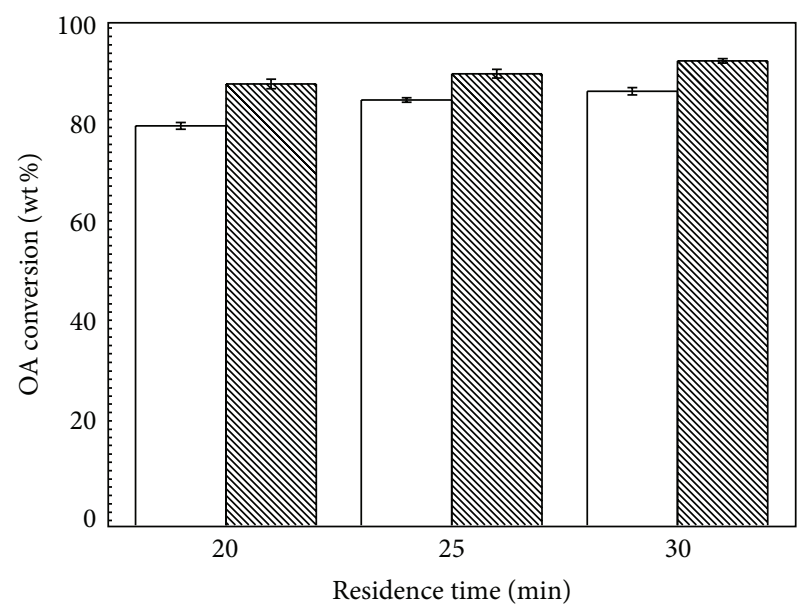

$15 \mathrm{MPa}$

$20 \mathrm{MPa}$

(a)

(b)

FIGURE 2: Effect of pressure on the conversion of oleic acid in molar ratio 1: 6 and temperature: $523 \mathrm{~K}$ (a) and $548 \mathrm{~K}$ (b).

3.2. Effect of Pressure. The effect of pressure on the esterification reaction was evaluated adopting the oleic acid to ethanol molar ratio of $1: 6$ and temperatures of $523 \mathrm{~K}$ and $548 \mathrm{~K}$, with results shown in Figure 2. As shown in Figure 2 an increase in pressure had a positive effect on the FAEE yield. At $523 \mathrm{~K}$ and $20 \mathrm{~min}$ of residence time, $85 \%$ of conversion is obtained at $20 \mathrm{MPa}$ and $\sim 75 \%$ at $15 \mathrm{MPa}$. At $548 \mathrm{~K}$ and residence time of $30 \mathrm{~min}, 93 \%$ of conversion is obtained at $20 \mathrm{MPa}$ and $86 \%$ at $15 \mathrm{MPa}$. The system pressure may have a great influence on the properties of a supercritical fluid near its critical point, such as density, hydrogen bound intensity, and viscosity. When the pressure was slightly higher than the critical pressure of ethanol ( 6.4 MPa), the yield was lower than at high pressure for both pressures [26]. The best reaction conversion was obtained at $20 \mathrm{MPa}$, consistent with the results reported in the literature for supercritical transesterification of vegetable oils in continuous mode [12, 26, 27].

3.3. Effect of Temperature and Residence Time. The effect of temperature and residence time in the noncatalytic esterification was evaluated keeping the oleic acid to ethanol molar ratio fixed at $1: 6$, pressure at $20 \mathrm{MPa}$, varying the temperature from $473 \mathrm{~K}$ to $598 \mathrm{~K}$, and residence time of 10 to 40 minutes. Figure 3 shows the OA conversion as a function of the temperature and residence time. As can be seen in Figure 3 , the conversion increases with temperature in the 


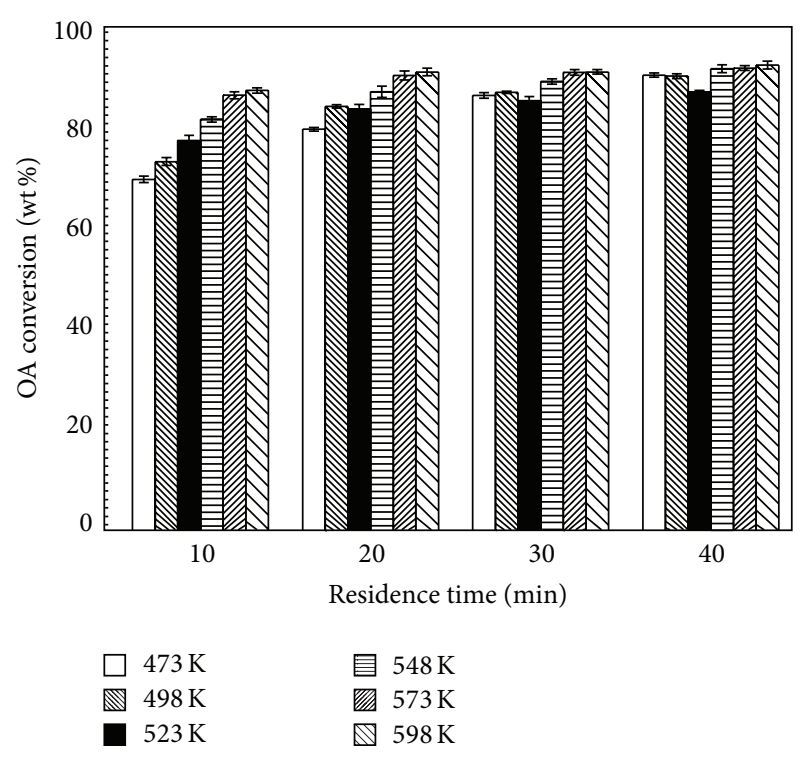

FIGURE 3: Effect of temperature on the conversion of oleic acid in molar ratio 1:6 and a pressure of $20 \mathrm{MPa}$.

range of $473 \mathrm{~K}$ to $573 \mathrm{~K}$ and no significant difference between the results obtained at $573 \mathrm{~K}$ and $598 \mathrm{~K}(P>0.05)$ was observed. For example, at $473 \mathrm{~K}$ after $10 \mathrm{~min}$ of reaction was obtained $\sim 70 \%$ of conversion, while $\sim 88 \%$ was reached for the same time for supercritical treatment at $573 \mathrm{~K}$.

Yujaroen et al. [13] evaluated the effect of temperature on the reaction of palm fatty acid distillate (PFAD) using supercritical methanol and reported, at PFAD to methanol molar ratio of $1: 6,10-15 \mathrm{MPa}$, and $30 \mathrm{~min}$ of reaction, $62 \%$ and $85 \%$ of conversion for $523 \mathrm{~K}$ and $563 \mathrm{~K}$, respectively. Ding et al. [16], in the esterification of oleic acid in a batch reactor at 10 min reaction time and using oleic acid to methanol molar ratio of $1: 9$, have obtained about $60 \%$ and $~ 85 \%$ of conversion for $523 \mathrm{~K}$ and $563 \mathrm{~K}$, respectively. The authors point out that increasing the temperature above $583 \mathrm{~K}$ does not cause a significant increase in the conversion. For reactions in continuous mode, Tsai et al. [22] mentioned the positive effect of temperature in the range of $493.2 \mathrm{~K}$ to $533.2 \mathrm{~K}$ on the OA conversion for esterification performed in a tubular reactor at $10 \mathrm{MPa}, 10 \mathrm{~min}$, and oleic acid to methanol molar ratio of $1: 5$, with conversions of $80 \%$ and $\sim 95 \%$ at $493.2 \mathrm{~K}$ and $533.2 \mathrm{~K}$, respectively.

It can be seen from Figure 3 that an increase in residence time of 10 to 30 minutes leads to a sharp enhancement of reaction conversions for temperatures of $573 \mathrm{~K}$ to $548 \mathrm{~K}$. Ding et al. [16] reported, at $573 \mathrm{~K}, 10-15 \mathrm{MPa}$, and oleic acid to methanol molar ratio of $1: 6$, OA conversion of $64 \%$ and $\sim 95 \%$ for reaction time of $10 \mathrm{~min}$ and $30 \mathrm{~min}$, respectively. For higher temperatures the residence time will not show a significant effect on the OA conversion. This behavior is evidence that the reaction at higher temperature and residence time more than 30 minutes reached thermodynamic equilibrium.

When comparing the experimental data obtained in this work with the literature results $[12,21]$, it can be seen that esterification reaction occurs with a higher rate than the transesterification reaction, resulting in higher yields in lower operational conditions. Thus, vegetable oils with high acid present as feedstock with potential for biodiesel production using a solvent in sub- or supercritical conditions. In recent work of the group, it may be observed that the content of free fatty acids influences the esters yield. Doná et al. [24] reported higher yields in the reaction of methyl acetate with Macaúba oil (39.62 wt $\%$ of FFA) when compared with the use of soybean oil ( $0.1 \mathrm{wt} \%$ of FFA). The use of Jatropha oil (10.1 wt\% of FFA) in the production of ethyl esters is presented in the study of Silva et al. [26] reported with high yields when compared with the results of Andrade [28] for using soybean oil under the same operating conditions. Schulte [29] reported the esterification of tall oil fatty acids, obtained by hydrolysis, at $573 \mathrm{~K}$ and 1650 psia using a methanol to feedstock ratio of $10: 1$, and showed esters yield of $82.3 \%$ from these free fatty acids, which is slightly higher than the yield obtained from the treatment of tall oil at these conditions (78.9\%).

\section{Conclusions}

Results obtained in the present work show that high conversion can be achieved for the noncatalytic reaction of oleic acid with compressed ethanol. In the experimental range investigated, temperature and pressure had a positive effect on reaction conversion. The results show that high conversions of oleic acid can be obtained with low ethanol concentrations in the reaction medium and low residence times.

\section{Conflict of Interests}

The authors declare no conflict of interests.

\section{Acknowledgments}

The authors thank $\mathrm{CNPq}$ and Fundação Araucária for the financial support and West Paraná State University (UNIOESTE) for the scholarship.

\section{References}

[1] L. C. Meher, D. Vidya Sagar, and S. N. Naik, "Technical aspects of biodiesel production by transesterification-a review," Renewable and Sustainable Energy Reviews, vol. 10, no. 3, pp. 248-268, 2006.

[2] A. P. Vyas, J. L. Verma, and N. Subrahmanyam, "A review on FAME production processes," Fuel, vol. 89, no. 1, pp. 1-9, 2010.

[3] M. Berrios, M. A. Martín, A. F. Chica, and A. Martín, "Study of esterification and transesterification in biodiesel production from used frying oils in a closed system," Chemical Engineering Journal, vol. 160, no. 2, pp. 473-479, 2010.

[4] K. Srilatha, T. Issariyakul, N. Lingaiah, P. S. Sai Prasad, J. Kozinski, and A. K. Dalai, "Efficient esterification and transesterification of used cooking oil using 12-tungstophosphoric acid (TPA) $/ \mathrm{Nb}_{2} \mathrm{O}_{5}$ catalyst," Energy and Fuels, vol. 24, no. 9, pp. 4748-4755, 2010. 
[5] L. T. Thanh, K. Okitsu, Y. Sadanaga, N. Takenaka, Y. Maeda, and H. Bandow, "A two-step continuous ultrasound assisted production of biodiesel fuel from waste cooking oils: a practical and economical approach to produce high quality biodiesel fuel," Bioresource Technology, vol. 101, no. 14, pp. 5394-5401, 2010.

[6] L. L. L. Rocha, A. L. D. Ramos, N. R. A. Filho, N. C. Furtado, C. A. Taft, and D. A. G. Aranda, "Production of biodiesel by a two-step niobium oxide catalyzed hydrolysis and esterification," Letters in Organic Chemistry, vol. 7, pp. 571-578, 2010.

[7] J. S. de Sousa, E. D. Cavalcanti-Oliveira, D. M. G. Freire, and D. A. G. Aranda, "Application of lipase from the physic nut (Jatropha curcas L.) to a new hybrid (enzyme/chemical) hydroesterification process for biodiesel production," Journal of Molecular Catalysis B, vol. 65, no. 1-4, pp. 133-137, 2010.

[8] D. T. Raspe, L. Cardozo-Filho, and C. Silva, "Effect of additives and process variables on enzymatic hydrolysis of macauba kernel oil (Acrocomia aculeata)," International Journal of Chemical Engineering, vol. 2013, Article ID 438270, 8 pages, 2013.

[9] D. Kusdiana and S. Saka, "Two-step preparation for catalyst-free biodiesel fuel production: hydrolysis and methyl esterification," Applied biochemistry and biotechnology, vol. 113-116, pp. 781-791, 2004.

[10] E. Minami and S. Saka, "Kinetics of hydrolysis and methyl esterification for biodiesel production in two-step supercritical methanol process," Fuel, vol. 85, no. 17-18, pp. 2479-2483, 2006.

[11] D. Kusdiana and S. Saka, "Biodiesel fuel from rapeseed oil as prepared in supercritical methanol," Fuel, vol. 80, no. 2, pp. 225231, 2001.

[12] C. Da Silva, F. De Castilhos, J. V. Oliveira, and L. C. Filho, "Continuous production of soybean biodiesel with compressed ethanol in a microtube reactor," Fuel Processing Technology, vol. 91, no. 10, pp. 1274-1281, 2010.

[13] D. Yujaroen, M. Goto, M. Sasaki, and A. Shotipruk, "Esterification of palm fatty acid distillate (PFAD) in supercritical methanol: effect of hydrolysis on reaction reactivity," Fuel, vol. 88, no. 10, pp. 2011-2016, 2009.

[14] R. Alenezi, G. A. Leeke, J. M. Winterbottom, R. C. D. Santos, and A. R. Khan, "Esterification kinetics of free fatty acids with supercritical methanol for biodiesel production," Energy Conversion and Management, vol. 51, no. 5, pp. 1055-1059, 2010.

[15] C.-H. Chen, W.-H. Chen, C.-M. J. Chang, S.-M. Lai, and C.-H. Tu, "Biodiesel production from supercritical carbon dioxide extracted Jatropha oil using subcritical hydrolysis and supercritical methylation," Journal of Supercritical Fluids, vol. 52, no. 2, pp. 228-234, 2010.

[16] J. Ding, B. He, and J. Li, "Biodiesel production from acidified oils via supercritical methanol," Energies, vol. 4, no. 12, pp. 22122223, 2011.

[17] K. White, N. Lorenz, T. Potts et al., "Production of biodiesel fuel from tall oil fatty acids via high temperature methanol reaction," Fuel, vol. 90, no. 11, pp. 3193-3199, 2011.

[18] H. J. Cho, S. H. Kim, S. W. Hong, and Y.-K. Yeo, "A single step non-catalytic esterification of palm fatty acid distillate (PFAD) for biodiesel production," Fuel, vol. 93, pp. 373-380, 2012.

[19] T. Pinnarat and P. E. Savage, "Noncatalytic esterification of oleic acid in ethanol," Journal of Supercritical Fluids, vol. 53, no. 1-3, pp. 53-59, 2010.

[20] Z. Ilham and S. Saka, "Two-step supercritical dimethyl carbonate method for biodiesel production from Jatropha curcas oil," Bioresource Technology, vol. 101, no. 8, pp. 2735-2740, 2010.
[21] I. Vieitez, C. D. Silva, I. Alckmin et al., "Effect of temperature on the continuous synthesis of soybean esters under supercritical ethanol," Energy and Fuels, vol. 23, no. 1, pp. 558-563, 2009.

[22] Y. Tsai, H. Lim, and M. Lee, "Biodiesel production with continuous supercritical process: non-catalytic transesterification and esterification with or without carbon dioxide," Bioresource Technology, vol. 143, pp. 362-369, 2013.

[23] A. Robles-Medina, P. A. González-Moreno, L. Esteban-Cerdán, and E. Molina-Grima, "Biocatalysis: towards ever greener biodiesel production," Biotechnology Advances, vol. 27, no. 4, pp. 398-408, 2009.

[24] G. Doná, L. Cardozo-Filho, C. Silva, and F. Castilhos, "Biodiesel production using supercritical methyl acetate in a tubular packed bed reactor," Fuel Processing Technology, vol. 106, pp. 605-610, 2013.

[25] R. E. Walker, Official Methods and Recommended Practices of the American Oil Chemists' Society (Method AOCS Ce 2-66), American Oil Chemists' Society, Champaign, Ill, USA, 4th edition, 1990.

[26] C. Silva, T. A. S. Colonelli, E. A. Silva, V. F. Cabral, J. V. Oliveira, and L. Cardozo-Filho, "Continuous catalyst-free production of esters from Jatropha curcasL. oil under supercritical ethanol," Brazilian Journal of Chemical Engineering. In press.

[27] C. M. Trentin, A. P. Lima, I. P. Alkimim et al., "Continuous production of soybean biodiesel with compressed ethanol in a microtube reactor using carbon dioxide as co-solvent," Fuel Processing Technology, vol. 92, no. 5, pp. 952-958, 2011.

[28] S. B. Andrade, Produção contínua de ésteres etílicos a partir do óleo de soja utilizando etanol supercrítico em leito estruturado [M.S. thesis], Universidade Estadual de Maringá, Maringa, Brazil, 2012.

[29] W. B. Schulte, Biodiesel production from tall oil and chicken fat via supercritical methanol treatment [M.S. thesis], University of Arkansas, Fayetteville, Ark, USA, 2007. 

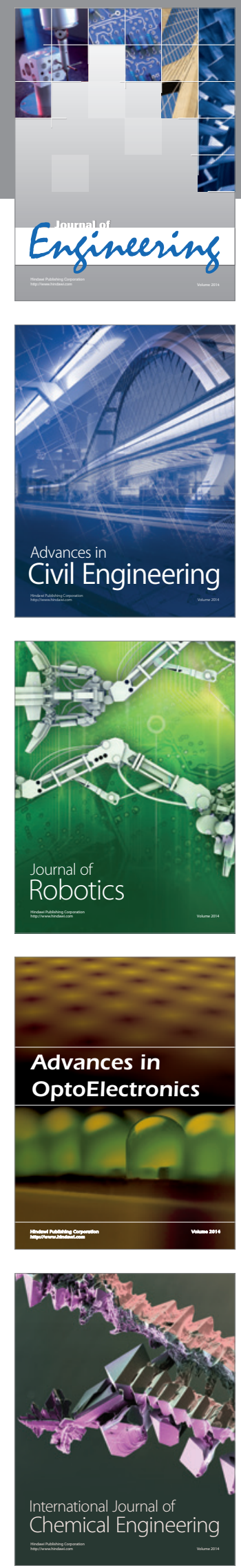

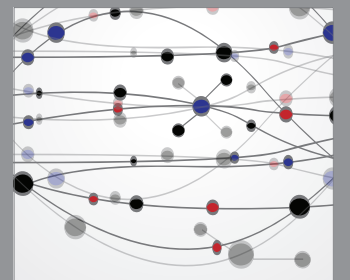

The Scientific World Journal
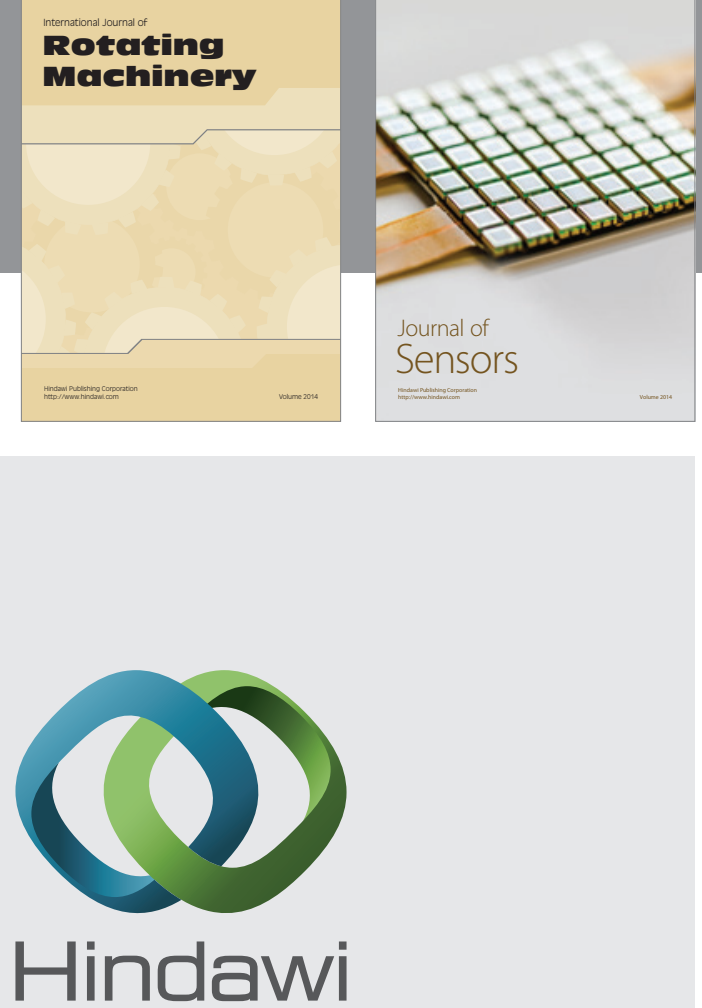

Submit your manuscripts at http://www.hindawi.com
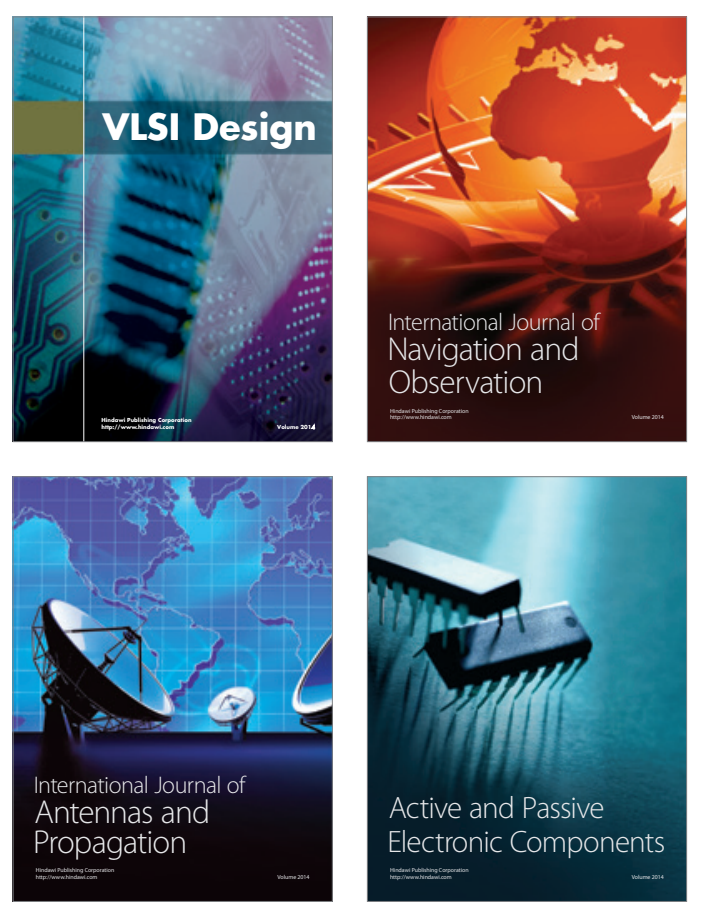
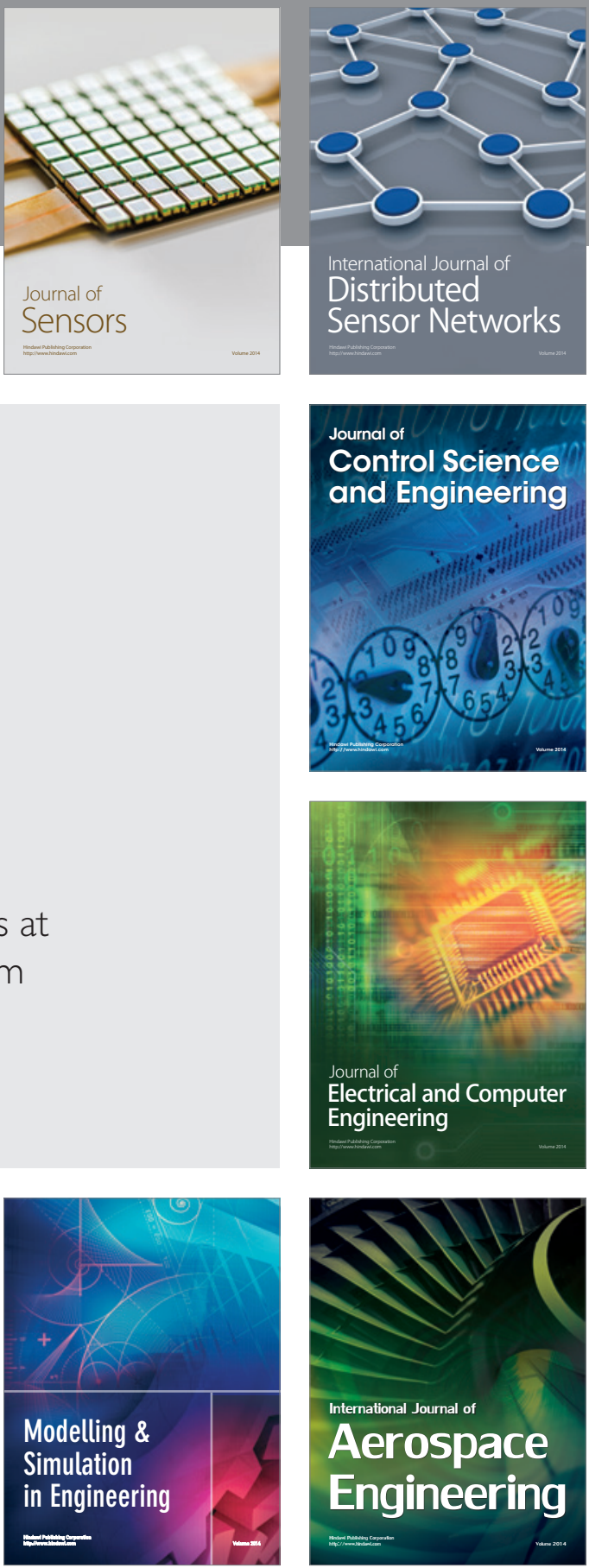

Journal of

Control Science

and Engineering
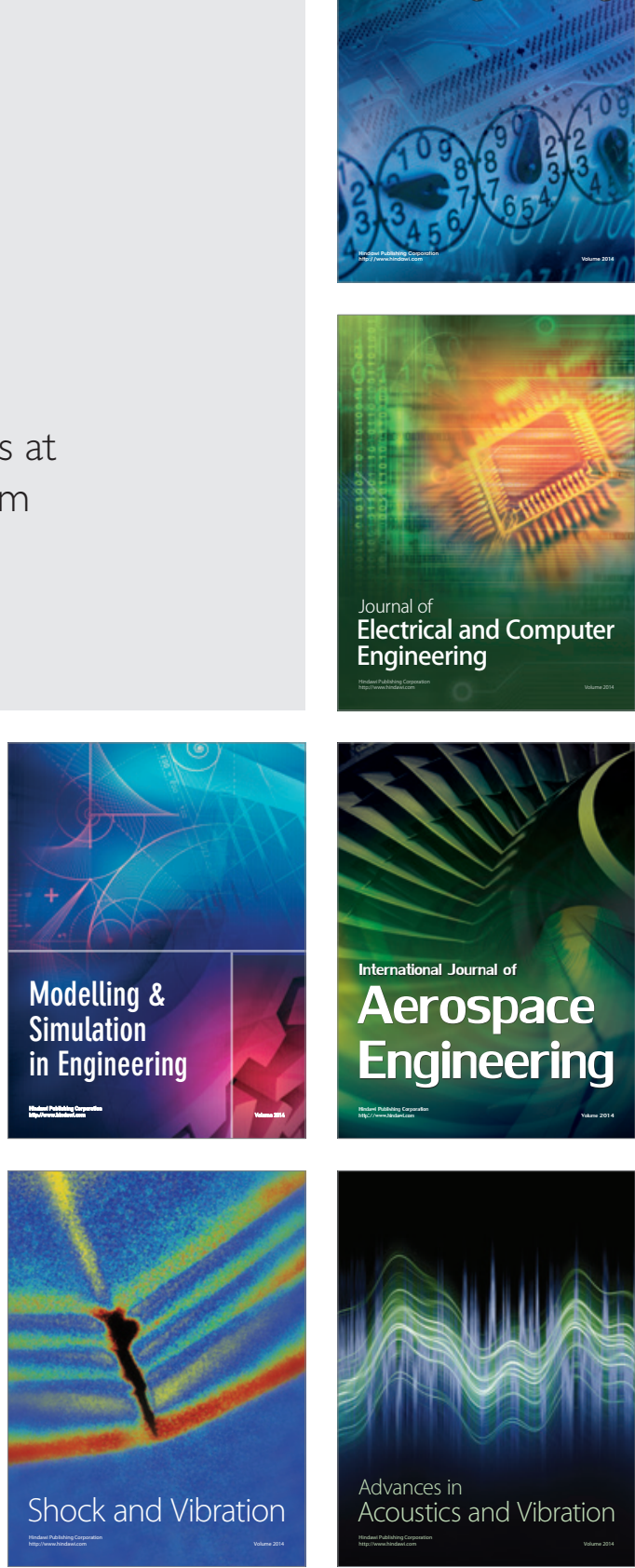